SHORT TITLE: Bullying victimisation in South African adolescents

Bullying victimisation, internalising symptoms, and conduct problems in South African children and adolescents: A longitudinal investigation

Mark E. Boyes ${ }^{a, b}$, Lucy Bowes $^{b}$, Lucie D. Cluver ${ }^{b, c}$, Catherine L. Ward ${ }^{d, e}$, \& Nicholas A. $\operatorname{Badcock}^{f}$

a: Health Psychology and Behavioural Medicine Research Group, School of Psychology and Speech Pathology, Curtin University, Perth, Australia

b: Centre for Evidence-Based Intervention, Department of Social Policy and Intervention, University of Oxford, United Kingdom

c: Department of Psychiatry and Mental Health, University of Cape Town, Cape Town, South Africa

d:, Department of Psychology, University of Cape Town, Cape Town, South Africa e: Safety and Violence Initiative, University of Cape Town, Cape Town, South Africa $f:$ ARC Centre of Excellence in Cognition and its Disorders, Department of Cognitive Science, Macquarie University, Sydney, Australia

\title{
Citation:
}

Boyes, M. E. Bowes, L., Cluver, L. D., Ward, C. L., \& Badcock, N. A. (2014). Bullying victimisation, internalising symptoms, and conduct problems in South African children and adolescents. A longitudinal investigation. Journal of Abnormal Child Psychology, 42, 13131324.

NOTICE: this is the author's version of a work that was accepted for publication in the Journal of Abnormal Child Psychology. Changes resulting from the publishing process, such as peer review, editing, corrections, structural formatting, and other quality control mechanisms may not be reflected in this document. Changes may have been made to this work since it was submitted for publication. A definitive version was subsequently published in the Journal of Abnormal Child Psychology, [Volume 42, Issue 8, 2014] DOI: 10.1007/s10802-014-9888-3. 


\begin{abstract}
Bullying victimisation has been prospectively linked with mental health problems among children and adolescents in longitudinal studies in the developed world. However, research from the developing world, where adolescents face multiple risks to social and emotional development, has been limited by cross-sectional designs. This is the first longitudinal study of the psychological impacts of bullying victimisation in South Africa. The primary aim was to examine prospective relationships between bullying victimisation and internalising and externalising symptoms in South African youth. Secondary aims were to examine gender and age-related differences in experiences of bullying victimisation. Children and adolescents (10-17 years, 57\% female, $n=3515)$ from high HIV-prevalent $(>30 \%)$ communities in South Africa were interviewed and followed-up one year later (97\% retention). Census enumeration areas were randomly selected from urban and rural sites in two provinces and door-to-door sampling included all households with a resident child/adolescent. Exposure to multiple experiences of bullying victimisation at baseline predicted internalising symptoms and conduct problems one year later. Additionally, baseline mental health scores predicted later bullying victimisation, demonstrating bi-directionality of relationships between bullying victimisation and mental health outcomes in this sample. Expected gender differences in physical, verbal, and relational bullying victimisation were evident and predicted declines in bullying victimisation over time were observed. In the developed world, school-based antibullying programmes have been shown to be effective in reducing bullying and victimisation. Anti-bullying programmes should be implemented and rigorously evaluated in South Africa, as this may promote improved mental health among South African children and adolescents.
\end{abstract}

Keywords: bullying, victimisation, anxiety, depression, adolescent, gender, South Africa 


\section{Bullying victimisation, internalising symptoms, and conduct problems in South African children and adolescents: A longitudinal investigation}

Bullying can be defined as repeated acts of aggressive behaviour intended to cause harm, and it is usually characterised by an imbalance in power between the perpetrator and the victim (Olweus, 1993; Rigby, 2002). Large studies in the US and Europe report that 20$30 \%$ of school-aged children and adolescents experience frequent bullying victimisation (Kaltiala-Heino, Rimpela, Rantanen, \& Rimpela, 2000; Nansel et al., 2004; Nansel et al., 2001; Shetgiri, Lin, \& Flores, 2012) and that this victimisation is associated with poorer psychosocial outcomes, in particular, internalising symptoms such as depression and anxiety (Arseneault et al., 2008; Brunstein Klomak, Marrocco, Kleinman, Schonfeld, \& Gould, 2007; Forero, McLellan, Rissel, \& Bauman, 1999; Ghoul, Niwa, \& Boxer, 2013; Hawker \& Boulton, 2000; Kaltiala-Heino et al., 2000; Reijntjes, Kamphuis, Prinzie, \& Telch, 2010; van der Wal, de Wit, \& Hirasing, 2003; Yen et al., 2013). Indeed, the accumulation of prospective, longitudinal research from the developed world, showing a dose-response association between bullying victimisation and internalising symptoms across different samples and using differing measures, offers strong support for the relationship between bullying victimisation and internalising symptoms (Arseneault, Bowes, \& Shakoor, 2010; Fekkes, Pijpers, Fredriks, Vogels, \& Verloove-Vanhorick, 2006). Studies have demonstrated that children who are bullied show an increase in internalising symptoms over time (Reijntjes et al., 2010), even after adjusting for effects of initial internalising symptoms (a risk factor for being victimized; Fekkes et al., 2006). A smaller body of research has additionally linked bullying victimisation with externalising symptoms, such as aggression, delinquency, and substance misuse (Arseneault et al., 2010; Khatri, Kupersmidt, \& Patterson, 2000; Schwartz, McFayden-Ketchum, Dodge, Pettit, \& Bates, 1998). 
Victim characteristics, such as age and gender, have also been examined as potentially exerting differential effects on the associations between bullying victimisation and mental health (Hawker \& Boulton, 2000; Reijntjes et al., 2010). Experiences of bullying victimisation have consistently been demonstrated to peak in early adolescence, a period during which children spend increasing amounts of time with their peers (Ghoul et al., 2013; Larson \& Richards, 1991) and increasingly value peer relationships and approval (Eccles et al., 1993). After this period, experiences of bullying victimisation reduce steadily with age (Nansel et al., 2001; Olweus, 1993; Rigby, 2002). Additionally, there are gender differences in mental health problems in adolescence, with girls being more likely to suffer internalising symptoms such as anxiety (Anderson, Williams, McGee, \& Silva, 1987; Lewinsohn, Gotlib, Lewinsohn, Seeley, \& Allen, 1998; McLean \& Anderson, 2009) and depression (Coelho, Martins, \& Barros, 2002; Giaconia et al., 1993) and boys more likely to show externalising symptoms (Kessler et al., 1994). However, it remains unclear whether the experience of bullying victimization may be differentially associated with mental health among boys and girls. To date, findings regarding differential mental health outcomes as a function of gender have been mixed (Kaltiala-Heino, Frojd, \& Marttunen, 2010), although a number of studies have reported stronger associations of bullying victimisation with internalising symptoms among girls than boys (Bond, Carlin, Thomas, Rubin, \& Patton, 2001; Kim, Koh, \& Leventhal, 2005; van der Wal et al., 2003; Yen et al., 2013).

Experiences of bullying victimisation can be categorised into direct and indirect victimisation. Direct bullying victimisation occurs during face-to-face interactions and includes physical and verbal behaviours such as kicking, hitting, threatening, name calling, and insulting. Indirect victimisation (also known as relational bullying) includes actions that do not necessarily need to occur in direct face-to-face interactions, such as spreading rumours, gossip, manipulating friendship groups, and social exclusion and isolation 
(Arseneault et al., 2010; van der Wal et al., 2003). Gender differences in the types of bullying victimisation experienced have been reported, with boys more likely to experience direct bullying victimisation and girls more likely to experience indirect/relational bullying victimisation (Bjorkqvist, Lagerspetz, \& Kaukiainen, 1992; Rivers \& Smith, 1994).

A major limitation of research on bullying and child and adolescent mental health is that to date almost all studies have been conducted in the developed world (Hawker \& Boulton, 2000). Ecological models of child and adolescent development (Bronfrenbrenner, 1979) posit cumulative and counterbalancing effects of risk and protective factors across a number of levels; e.g. individual, family, and cultural. As yet, it is unclear whether bullying victimisation remains a salient risk factor in the face of multiple developmental risks experienced by children and adolescents in low-income countries (Brown, Riley, Butchart, \& Kann, 2008; Hawker \& Boulton, 2000). Children and adolescents in South Africa face a number of risks to their social and emotional development, including extreme poverty (Cluver, Gardner, \& Operario, 2009), high levels of abuse (Richter \& Dawes, 2008), the impact of the HIV/AIDS epidemic (Cluver, Orkin, Boyes, Gardner, \& Nikelo, 2012), as well as high levels of interpersonal and community violence (Burton, 2008). Although a number of cross-sectional studies have demonstrated links between bullying victimisation and negative mental health outcomes even in the context of these substantial risks to social and emotional development (Cluver, Bowes, \& Gardner, 2010; Liang, Flisher, \& Lombard, 2007; Shields, Nadasen, \& Pierce, 2009; Siziya, Muula, \& Rudatsikira, 2007), to date, this has not yet been examined using prospective methodologies.

Bullying victimisation in South Africa is widespread. Data from a nationally representative sample of high school students put prevalence rates at $41 \%$ (Reddy et al., 2003), although prevalence rates as high as $61 \%$ have been reported (Townsend, Flisher, Chikobvu, Lombard, \& King, 2008). Three South African studies have demonstrated 
relationships between victimisation and internalising symptoms; including symptoms of anxiety, depression, posttraumatic stress (Cluver et al., 2010; Shields et al., 2009), and suicidal ideation (Liang et al., 2007). Additionally, bullying victimisation has been associated with externalising symptoms (violence and antisocial behaviour, Liang et al., 2007) as well as school truancy, and dropout (Siziya et al., 2007) in South African youth. It should be noted however that the cross-sectional design of all these studies has precluded any conclusions regarding the direction of association between bullying victimisation and internalising and externalising symptoms in South African children and adolescents. This has prompted calls from prominent South African academics for longitudinal studies to address this issue (Liang et al., 2007).

Consistent with research from the developed world, rates of bullying victimisation in South Africa are higher among younger children and adolescents (Grade 8 versus Grade 11, Flisher et al., 2006). With regard to gender differences in bullying victimisation, Liang and colleagues (2007) report that, overall, males experience more bullying victimisation than females; however, no studies to date have examined gender differences in the categories of bullying victimisation experienced by South African children and adolescents. Additionally no studies in South Africa have examined the potential moderating effects of gender on relationships between bullying victimisation and mental health outcomes.

To the best of our knowledge the current research represents the first prospective study of bullying victimisation and mental health outcomes (both internalising and externalising) in a South African sample. The primary aims of the study were to i) examine cross-sectional and longitudinal relationships between bullying victimization and both internalising (anxiety, depression, and posttraumatic stress) and externalising (conduct problems) symptoms in South African children and adolescents, ii) assess potential bidirectionality of associations between these constructs, and iii) examine continuity of 
exposure to bullying victimisation over time. Given previous longitudinal findings in the developed world and cross-sectional findings from South Africa, it was hypothesized that bullying victimisation would predict internalising symptoms and conduct problems both cross-sectionally and longitudinally, that relationships between bullying victimisation and mental health outcomes would be bi-directional (such that mental health at baseline assessment would also predict later bullying victimisation), and that bullying victimisation at baseline assessment would be associated with bullying victimisation at follow-up assessment. Secondary aims of the study were to examine gender and age-related differences in experiences of bullying victimisation among South African children and adolescents. Based on research from the developed world it was hypothesized that boys would experience more direct bullying victimisation, girls would experience more indirect/relational bullying victimisation, and that there would be age-related declines in bullying victimisation over time. Given the mixed findings in the previous international literature, no specific hypotheses regarding the potential moderating effects of gender on the relationships between bullying victimisation and internalising and externalising symptoms were formulated.

\section{Method}

\section{Participants}

Children and adolescents $(n=3515)$ from rural and urban sites in two South African provinces (the Western Cape and Mpumalanga) took part in a community-based survey. Two provinces were chosen to ensure that a range of different language groups were represented in the sample. Participants in the Western Cape spoke isiXhosa and participants in Mpumalanga spoke Sesotho or Xitsonga. Children and adolescents were recruited using stratified random sampling of census enumeration areas in four health districts with over $30 \%$ antenatal HIV- 
prevalence. The areas from which participants were sampled are extremely poor and characterised by high levels of community violence (at baseline assessment $41 \%$ of participants had witnessed someone being shot or stabbed). On average households were lacking nearly three of the eight basic necessities identified in the South African Social Attitudes Survey as being a basic need for all children and adolescents in South Africa (see measures section for a description of these needs). All households in randomly selected enumeration areas were sampled consecutively (door-to-door) and one child/adolescent per household (randomly selected if there were multiple children in the household) participated in the study. Participants were followed up after one year (97\% retention rate, a loss to followup of 114 participants). Ages ranged between 10 and 17 years at baseline $(M=13, S D=2.15)$ and $57 \%$ of the sample were female. A summary of sample characteristics for both baseline and follow-up assessment periods is provided in Table 1.

\section{(Insert Table 1 approximately here)}

\section{Measures}

Bullying victimisation was measured at both baseline and follow-up assessment with the nine-item Social and Health Assessment Peer Victimisation Scale (Ruchkin, SchwabStone, \& Vermeiren, 2004). This scale has been adapted from the Multidimensional Peer Victimisation Scale, which showed excellent reliability $(\alpha=.82)$ in a US sample (Mynard \& Joseph, 2000). Items are responded according to frequency in the past year (1: Never, 2: Once, 3: Two to three times 4: Four or more times). This scale has been used previously with this age group in South Africa (Cluver et al., 2010) and demonstrated excellent reliability in the current sample $(\alpha=.81)$. The scale contains two items measuring physical bullying victimisation (e.g. punched, kicked, or beat me up), two items measuring verbal bullying 
victimisation (e.g. called me names or swore at me), two items measuring relational bullying victimisation (e.g. refused to talk to me or made other people not talk to me), two items measuring victimisation through property damage and theft (e.g. tried to break or damaged something of mine), and a single item assessing invasion of physical space. Total bullying victimisation scores were calculated by summing all items. Additionally, two bullying victimisation dichotomies were created from the total scale score for both assessment periods: 1) experienced any bullying victimisation in the past year, and 2) following a previous South African study, experiencing multiple (four or more) types of bullying victimisation in the past year (Cluver et al., 2010). As the definition of bullying victimisation emphasises the repeated nature of exposure to aggressive experiences (Olweus, 1993; Rigby, 2002), only participants who experienced two or more incidents of victimisation in the past year were classified as being bullied. Participants who reported that victimisation had only occurred once in the past year were coded into the 'not bullied' category for both dichotomies. It should be noted that the Social and Health Peer Victimisation Scale does not capture the notion of power imbalance that is central to many definitions of bullying victimisation (Olweus, 1993), and results should be interpreted with this in mind.

Anxiety was measured at baseline and follow-up assessments using an abbreviated version of the Revised Children's Manifest Anxiety Scale (RCMAS; Reynolds \& Richmond, 1978). Only the 14 highest loading items, identified through factor analysis in a previous study (Cluver, Orkin, Gardner, \& Boyes, 2012) were administered. Example items include "I worry a lot of the time" and "I am nervous" and are responded to on a no/yes scale. Total anxiety scores were calculated by summing all items. The RCMAS has been validated for use with South African samples (Boyes \& Cluver, 2013a) and the abbreviated version demonstrated excellent reliability in the current sample $(\alpha=.81)$. 
Depression was measured at baseline and follow-up assessments with the 10-item Children's Depression Inventory - Short Form (CDI-SF; Kovacs, 1992). The inventory contains a range of symptoms and participants are asked to choose one statement that best reflects their feelings in the past two weeks. The short form is well validated and highly correlated with the full version $(r=.89$; Kovacs, 1992) and has been used previously in South Africa samples (Boyes \& Cluver, 2013b; Cluver, Gardner, \& Operario, 2007). Total depression scores were calculated by summing all items. The inventory demonstrated adequate reliability in the current sample $(\alpha=.74)$.

Posttraumatic stress symptoms were measured at both assessments using the 28 -item Child PTSD Checklist (Amaya-Jackson, McCarthy, Cherney, \& Newman, 1995). The checklist rates the presence (in the past month) of 17 symptoms required by DSM-IV for a diagnosis of PTSD. Items are responded to on a four-point frequency scale (0: Not at all; 1 : Some of the time; 2: Most of the time; 3: All the time). Example symptoms include getting jumpy or startling easily and having trouble falling or staying asleep. Total scores were calculated by summing all items. The Child PTSD Checklist is frequently used in South African samples (Seedat, Nyamai, Njenja, Vythilingum, \& Stein, 2004; Suliman et al., 2009) and has been validated for use in this context (Boyes, Cluver, \& Gardner, 2012). The checklist demonstrated adequate reliability in the current sample $(\alpha=.74)$.

Conduct problems in the preceding six months were measured at both assessment points using the five-item conduct problems subscale of the Strengths and Difficulties Questionnaire (Goodman, 1997; Goodman, Meltzer, \& Bailey, 1998). Items are responded to on a three-point scale (0: Not true, 1: Somewhat true, 3: Definitely true) and are summed to give a total conduct problems score. Example items include "I get very angry and often lose my temper" and "I am often accused of lying or cheating". The Strengths and Difficulties Questionnaire is well-validated and has been used previously in South African studies 
(Cortina et al., 2013). Internal consistency in the current sample was low $(\alpha=.47)$; however, $\alpha$ may be underestimated when there are only few items (Tavakol \& Dennick, 2011). We therefore checked item-total correlations. All item-total correlations were substantially above the $r=.30$ threshold recommended by Field (2005) and ranged between $r=.41$ and $r=.69$.

Household poverty was measured at baseline assessment using an index of access to the eight highest socially-perceived necessities for children and adolescents in South Africa. These were identified through focus groups (Barnes \& Wright, 2012), followed by corroboration by over $80 \%$ of those sampled in the nationally representative South African Social Attitudes Survey (Pillay, Roberts, \& Rule, 2006). Items included: three meals per day, a visit to the doctor when needed, medicines when needed, enough clothes to remain warm and dry, soap to wash every day, money for school fees, school uniform, and more than one pair of shoes. Items were reverse-scored (0: Has access to the necessity; 1: Does not have access to the necessity) and summed to give a total poverty score (total number of necessities lacking).

Additional socio-demographic variables included age and gender of the children and adolescents, province, and whether the participant lived in an urban or rural location (all measured at baseline assessment).

\section{Procedure}

Ethical approval for this observational study was obtained from the Universities of Oxford, Cape Town, and KwaZulu-Natal, as well as the Provincial Health and Education Departments of the Western Cape, Mpumalanga, and KwaZulu-Natal. Prior to participation, voluntary informed assent was provided by the participant and voluntary informed consent by their caregivers. All measures were translated (and translations checked by back-translation) into local languages, and children and adolescents participated in the language of their 
choice. Measures were administered verbally at both assessment points by research assistants. All assistants were trained and had previous experience working with vulnerable children. The questionnaire booklet was designed in the style of a teen magazine and included pictures of popular music and television stars. In total, participation took approximately 60 minutes at both baseline and follow-up assessment points. No incentive for participation was provided. Confidentiality was maintained unless participants requested assistance or were at significant risk of harm.

\section{Analyses}

Analyses were conducted in SPSS 22 and AMOS 21 in five stages. First, we checked for any differences in sociodemographic characteristics, internalising symptoms and conduct problem scores, and experiences of bullying victimisation between participants lost and retained at follow-up. Second, predicted prospective relationships between bullying victimisation and internalising symptoms and conduct problems scores were tested using univariate ANCOVAs (adjusting for gender, age, poverty, urban versus rural location, and province). Third, cross-lagged path models additionally adjusted for baseline mental health and tested predicted bi-directional relationships between bullying victimisation and mental health outcomes. Fourth, hypothesized gender differences in bullying victimisation, internalising symptoms, and conduct problems were examined using univariate ANCOVAs (adjusting for age, poverty, urban versus rural location, and province). Finally, bullying victimisation*gender interaction terms were calculated and included in regression analyses in order to determine if prospective relationships between bullying victimisation and both internalising symptoms and conduct problem scores were moderated by gender. 
Results

\section{Children lost and retained at follow-up}

Youth lost to follow-up did not differ with regard to gender $\left[\chi^{2}(1)=.07, p=.789\right]$, experiences of baseline bullying victimisation $[F(1,3514)=1.85, p=.174$, Cohen's $d=$ $0.12]$, anxiety $[F(1,3512)=2.25, p=.134$, Cohen's $d=0.14]$, posttraumatic stress $[F(1$, $3506)=2.66, p=.103$, Cohen's $d=0.15]$, or conduct problem $[F(1,3508)=1.03, p=.310$, Cohen's $d=0.10$ ] scores. However, participants lost to follow-up were missing more basic necessities $[F(1,3514)=21.55, p<.001$, Cohen's $d=0.36]$, older $[F(1,3512)=6.44, p=$ .011 , Cohen's $d=0.24]$, and had higher depression scores at baseline assessment $[F(1,3512)$ $=8.98, p=.003$, Cohen's $d=0.26]$. Although a follow-up rate of $97 \%$ after one year is exceptional, some of the most vulnerable participants could not be traced and results should be interpreted with this in mind. The sample was limited to youth assessed at both time points for all further analyses.

Prospective associations between bullying victimisation, internalising symptoms, and conduct problems

Table 2 summarises differences in anxiety, depression, posttraumatic stress, and conduct problem scores at follow-up assessment as a function of bullying victimisation at baseline. After adjusting for sociodemographic variables, participants who reported any bullying victimisation obtained significantly higher anxiety (Cohen's $d=0.17$ ), posttraumatic stress (Cohen's $d=0.07$ ), and conduct problems scores (Cohen's $d=0.16$ ) at follow-up assessment, although effects were small. In contrast, moderate to large effects were obtained when outcomes were examined by multiple victimisation experience. Adolescents who experienced four or more types of bullying victimisation obtained significantly higher anxiety 
(Cohen's $d=0.78$ ), depression (Cohen's $d=0.40$ ), posttraumatic stress (Cohen's $d=0.42$ ), and conduct problems (Cohen's $d=0.58$ ) scores at follow-up.

\section{(Insert Table 2 approximately here)}

In order to determine whether these prospective associations between bullying victimisation and both internalising symptoms and conduct problems survived when simultaneously including internalising symptoms, conduct problems, and bullying victimisation from both assessment points, two cross-lagged models were constructed and tested using a path analysis framework. Models additionally adjusted for age, gender, urban versus rural location, and province. Analyses were conducted in AMOS 21 using the Bayesian estimation procedure (as maximum likelihood estimation cannot be used when models contain dichotomous endogenous variables; Blunch, 2008). This estimation procedure provides estimates and $95 \%$ confidence intervals for each parameter in the model, but does not output fit statistics for the overall model. Anxiety, depression, and posttraumatic stress scores were significantly correlated at both assessment points $(r=.19$ to $r=.51)$, therefore these scores were used to create a composite internalising symptoms variable (anxiety, depression, and posttraumatic stress scores were standardised to ensure equal weighting in the composite variable).

After adjusting for age, gender, poverty, urban versus rural location, and province, and including baseline internalising symptoms and conduct problem scores in the models, having experienced any bullying victimisation at baseline was not prospectively associated

with either internalising symptoms or conduct problem scores. However, experiencing four or more types of bullying victimisation at baseline prospectively predicted both internalising symptoms $(\beta=.04, p<.05)$ and conduct problem scores $(\beta=.04, p<.05)$ one year later. 
Additionally, baseline internalising symptoms $(\beta=.08, p<.05)$ and conduct problem scores $(\beta=.05, p<.05)$ were both significant predictors of multiple bullying victimisation at follow-up assessment, and multiple bullying victimisation at baseline assessment was significantly associated with multiple bullying victimisation one year later (Figure 1).

\section{(Insert Figure 1 approximately here)}

Gender differences in bullying victimisation, internalising symptoms, and externalising symptoms

Descriptive statistics related to bullying victimisation, internalising symptoms, and externalising behaviour at both assessment points are presented in Table 3, disaggregated by gender. Gender differences were examined using univariate ANCOVA (adjusting for age, poverty, urban versus rural location, and province) and chi-square analyses. There were no gender differences in total bullying victimisation scores or in the probability of having ever been bullied or experiencing four or more types of bullying victimisation in the past year. However, there were small but significant gender differences in the categories of bullying victimisation experienced by males and females. Males reported significantly more physical bullying victimisation than females at both baseline (Cohen's $d=0.09$ ) and follow-up (Cohen's $d=0.11$ ) assessment. Males also reported more verbal bullying victimisation at both baseline (Cohen's $d=0.11$ ) and follow-up (Cohen's $d=0.12)$. Females reported significantly more relational bullying victimisation than males at baseline (Cohen's $d=0.12$ ). At follow-up the gender difference in relational bullying victimisation was approaching significance ( $p=.073$, Cohen's $d=0.06)$.

\section{(Insert Table 3 approximately here)}


Small but significant gender differences were also obtained for all measures of internalising symptoms and conduct problems. Females reported significantly higher anxiety scores than males at both baseline (Cohen's $d=0.18$ ) and follow-up (Cohen's $d=0.15$ ). Females also obtained higher posttraumatic stress scores at both baseline (Cohen's $d=0.18$ ) and follow-up (Cohen's $d=0.16$ ). Additionally, females reported significantly higher depression scores than males at baseline assessment (Cohen's $d=0.18$ ). At follow-up assessment the gender difference in depression scores was approaching significance $(p=$ .089 , Cohen's $d=0.08)$. Males obtained significantly higher scores on the conduct problems measure than females at both baseline (Cohen's $d=0.12$ ) and follow-up assessments (Cohen's $d=0.15)$.

For both males and females there were small but significant reductions in total bullying victimisation scores over time $[$ Males: $F(1,1473)=42.71, p<.001$, Cohen's $d=$ 0.20; Females: $F(1,1921)=61.65, p<.001$, Cohen's $d=0.23]$. Similarly, for both genders there were reductions in the proportion of participants reporting having experienced any bullying victimisation or having experienced four or more types of bullying victimisation across time (Table 2). There were also small but significant reductions for both genders in anxiety $[$ Males: $F(1,1471)=62.32, p<.001$, Cohen's $d=0.27$; Females: $F(1,1922)=$ 109.18, $p<.001$, Cohen's $d=0.29$ ] and depression [Males: $F(1,1472)=13.06, p<.001$, Cohen's $d=0.12$; Females: $F(1,1921)=53.67, p<.001$, Cohen's $d=0.22]$ scores. There was a significant reduction in posttraumatic stress scores over time for males $[F(1,1465)=$ $7.26, p=.007$, Cohen's $d=0.10]$ but not females $[F(1,1907)=.12, p=.724$, Cohen's $d=$ 0.01]. There were no reductions in conduct problem scores over time for either males $[F(1$, $1471)=.23, p=.633$, Cohen's $d=0.02]$ or females $[F(1,1919)=.12, p=.734$, Cohen's $d=$ $0.01]$. 
Potential moderating effects of gender on relationships between bullying victimisation, internalising symptoms, and conduct problems

Finally, in order to determine whether gender moderated the prospective relationships between experiencing multiple types of bullying victimisation and both internalising symptoms and conduct problem scores, an interaction term was created (bullying victimisation*gender). This interaction was tested in simple linear regression models (including only the interaction term and its associated main effects), which were run separately for internalising symptoms and conduct problem scores. Gender was not a significant moderator of the relationships between multiple bullying victimisation and either internalising symptoms $(\beta=.07, p=.239)$ or conduct problem scores $(\beta=-.04, p=.531)$.

\section{Discussion}

To the best of our knowledge, this is the only prospective study of bullying victimisation and child and adolescent mental health in South Africa. The primary aims of the study were to examine i) cross-sectional and longitudinal relationships between bullying victimization and both internalising (anxiety, depression, and posttraumatic stress) and externalising (conduct problems) symptoms in South African children and adolescents, ii) potential bi-directionality of associations between these constructs, and iii) the continuity of exposure to bullying victimisation over time. Secondary aims were to examine gender and age-related differences in experiences of bullying victimisation among South African children and adolescents. Consistent with previous studies from South Africa (Reddy et al., 2003; Townsend et al., 2008), experiences of bullying victimisation were high. Over $50 \%$ of children and adolescents had experienced bullying victimisation of any kind in the past year 
at baseline and over $45 \%$ had experienced bullying victimisation of any kind in the past year at follow-up assessment.

After adjusting for sociodemographic characteristics, initial analyses showed small but significant effects of having experienced any bullying victimisation at baseline on both internalising symptoms and conduct problems measured at follow-up. Furthermore, these effects were amplified in children who had experienced four or more types of bullying victimisation (Table 2). Additionally, cross-lagged models demonstrated that bullying victimisation at baseline assessment was predictive of both internalising symptoms and conduct problems measured one year later, after additionally adjusting for baseline mental health scores (Figure 1). However, this was only the case for children and adolescents who experienced multiple types of bullying victimisation. This finding extends previous crosssectional results from South Africa (Cluver et al., 2010; Liang et al., 2007; Shields et al., 2009), and is also consistent with longitudinal studies from the developed world demonstrating prospective links between bullying victimisation and child and adolescent mental health (Reijntjes et al., 2010). Moreover, this appears to be the case even after adjusting for poverty and in a context where adolescents are exposed to multiple other risks to social and emotional development (Cluver et al., 2010).

Consistent with prospective studies from the developed world (Fekkes et al., 2006), children and adolescents with more internalising symptoms and higher conduct problem scores at baseline were also more likely to experience multiple instances of bullying victimisation at follow-up assessment. To the best of our knowledge, these are the first findings to clearly demonstrate bi-directionality of relationships between bullying victimisation and mental health outcomes in a South African sample. Additionally, as hypothesized, bullying victimisation at baseline was significantly associated with bullying victimisation at follow-up. This suggests that those children who initially experience bullying 
victimisation are also more likely to be the same children who experience bullying victimisation at later periods, even though overall rates of bullying victimisation reduce over time. In order to identify at risk children and adolescents in the South African context, longitudinal research examining factors associated with vulnerability to bullying victimisation is required (Cluver et al., 2010). Socio-ecological models (e.g. Bronfrenbrenner, 1979) provide a useful conceptual framework to inform research in this domain but are generic in that they do not indicate specific constructs to be measured. Therefore, the development of theoretical frameworks that incorporate specific social, biological, and ecological mechanisms is needed to underpin future research in this area.

A recent systematic review (Vreeman \& Carroll, 2007) and meta-analysis (Ttofi \& Farrington, 2011) of anti-bullying interventions in the developed world both concluded that anti-bullying programmes are effective in reducing bullying and victimisation (with average reductions of $17-23 \%$, Ttofi \& Farrington, 2011), although the chances of success are greater when interventions incorporate a whole-school approach involving multiple disciplines and the whole school community (Vreeman \& Carroll, 2007). Additionally, a recent trial from Finland has demonstrated that an anti-bullying intervention was successful in reducing bullying behaviours and that this in turn was associated with reductions in internalising symptoms among children (Williford et al., 2012). Given that many of the risks experienced by South African youth occur at the structural or community level and are difficult to change in the short-term (such as extreme poverty, community violence, and exceptionally high HIVprevalence rates), identifying and targeting potentially modifiable risk factors (such as bullying victimisation) may be important in improving the mental health of South African children and adolescents. Bullying prevention programmes should therefore be trialled and rigorously evaluated in South Africa. 
No gender differences in total bullying victimisation were obtained; however, consistent with research from the developed world (Bjorkqvist et al., 1992; Rivers \& Smith, 1994) gender differences in the categories of bullying victimisation were identified. Boys experienced more physical and verbal bullying victimisation than girls at both baseline and follow-up assessments. Girls experienced more relational bullying victimisation at baseline assessment and this gender difference was approaching significance at follow-up assessment $(p=.073)$. Additionally, consistent with previous research from the developed world (Nansel et al., 2001; Olweus, 1993; Rigby, 2002) and South Africa (Flisher et al., 2006) reporting age-related declines in bullying victimisation, there were significant reductions in experiences of bullying victimisation across time for both genders (Table 3). Although hypothesized gender differences in internalising symptoms and conduct problems were obtained, gender did not moderate the relationship between bullying victimisation and either internalising symptoms or conduct problems. However, given gender differences in direct and indirect/relational bullying victimisation were observed, future research should examine whether direct and indirect bullying victimisation are differentially associated with mental health outcomes and whether gender moderates these relationships. There is some evidence from the developed world that exposure to indirect bullying victimisation is more strongly associated with internalising symptoms (depression and suicidal ideation) than exposure to direct bullying victimisation (van der Wal et al., 2003), but to date this has not been examined in South Africa or other developing world contexts.

This study had a number of methodological limitations that should be acknowledged. First, reliably measuring both bullying victimisation as well as internalising and externalising symptoms in children is notoriously difficult due to problems with social desirability and limitations in children's ability to reliably report subjective states of internal distress (Michael \& Merrell, 1998; Salmivalli \& Peets, 2009). These problems may have been amplified 
through the use of interviewers, although this is also a potential strength of the study (in terms of minimising missing data and children's understanding of questionnaire items in the context of low literacy; Mulis, Martin, Kennedy, \& Foy, 2007). Additionally, as mentioned previously, the Social and Health Peer Victimisation Scale does not capture the notion of power imbalance that is central to many definitions of bullying victimisation (Olweus, 1993), and results should be interpreted with this in mind. Related to these issues of measurement, designs relying exclusively on self-report are at risk of method overlap bias. Specifically, youth who are anxious or depressed may feel more isolated and threatened and thus perceive higher levels of victimisation. Whilst the use of longitudinal data reduces this problem to an extent, given that baseline mental health scores are controlled for when predicting mental health measured at follow-up, future research should attempt to include teacher and/or peer nominations of bullying victimisation alongside youth self-reports. Second, although the follow-up retention rate was high $(97 \%)$, results must be interpreted in light of the fact that some of the most vulnerable children and adolescents were among those unable to be traced, and thus our findings may have underestimated the strengths of the observed relationships. Third, participants were sampled from high HIV-prevalence sites, and the South African context these are low-incomes and the population primarily black African. Therefore, findings are not generalizable to low HIV-prevalence areas, high-income areas, or other ethnic groups. However, the study did benefit from within-sample variation, including urban and rural areas in two provinces, and three language groups. Finally, the current study had a focus on gender as a potential moderator. Future research should explore the possible moderating and mediating effects of additional factors that could also be potential intervention foci, such as coping (Visconti \& Troop-Gordon, 2010), contingent self-worth (Ghoul et al., 2013), and social support (Cluver et al., 2010; Rothon, Head, Klineberg, \& Stansfeld, 2011). 
Bearing these limitations in mind, the current study provides the first evidence from South Africa that bullying victimisation is prospectively associated with mental health (both internalising and externalising symptoms) amongst children and adolescents. This is the case even in a context where youth are exposed to multiple other risks to their social and emotional development and after adjusting for household poverty. These findings emphasise the need for the implementation and rigorous evaluation of bullying prevention programmes in these South African communities. Findings also establish the bi-directionality of relationships between bullying victimisation and mental health in South African contexts, document gender differences in exposure to specific categories of bullying victimisation, and demonstrate that exposure to bullying victimisation appears to persist over time (even when overall rates of bullying victimisation fall). Furthering our understanding of associations between bullying victimisation and child and adolescent mental health, as well as whether these relationships are moderated by factors such as coping, self-worth, and social support will be an important next step in informing intervention and mental health promotion efforts in South Africa. 
Bullying victimisation in South African children and adolescents 23

\section{$\underline{\text { Acknowledgements }}$}

This study was funded by the UK Economic and Social Research Council, the South African National Research Foundation, the Health Economics and HIV/AIDS Research Division (HEARD) at the University of KwaZulu-Natal, the South African National Department of Social Development, the Claude Leon Foundation, the John Fell Fund, and the Nuffield Foundation. The authors wish to thank the South African fieldwork teams and all the participants and their families.

\section{Conflict of Interests}

None of the authors have any conflicts of interest to declare 
Bullying victimisation in South African children and adolescents 24

\section{References}

Amaya-Jackson, L., McCarthy, G., Cherney, M. S., \& Newman, E. (1995). Child PTSD Checklist $\bigcirc$. Durham, NC: Duke University Medical Center.

Anderson, J. C., Williams, S. M., McGee, R., \& Silva, P. A. (1987). DSM-III disorders in preadolescent children: Prevalence in a large sample from the general population. Archives of General Psychiatry, 44, 69-76.

Arseneault, L., Bowes, L., \& Shakoor, S. (2010). Bullying victimization in youths and mental health problems: 'Much ado about nothing'? Psychological Medicine, 40, 717-729.

Arseneault, L., Milne, B. J., Taylor, A., Adams, F., Delgado, K., Caspi, A., \& Moffitt, T. E. (2008). Being bullied as an environmentally mediated contributing factor to children's internalizing problems: A study of twins discordant for victimization. Archives of Pediatric and Adolescent Medicine 162, 145-150.

Barnes, H., \& Wright, G. (2012). Defining child poverty in South Africa using the socially percieved necessities approach. In A. Minujin (Ed.), Global Child Poverty and WellBeing: Measurement, Concepts, Policy and Action. Bristol: The Policy Press.

Bjorkqvist, K., Lagerspetz, K. M. J., \& Kaukiainen, A. (1992). Do girls manipulate and boys fight? Developmental trends in regard to direct and indirect aggression. Aggressive Behavior, 18, 117-127.

Blunch, N. J. (2008). Introduction to structural equation modelling using SPSS and AMOS. London: Sage.

Bond, L., Carlin, J., Thomas, L., Rubin, K., \& Patton, G. (2001). Does bullying cause emotional problems? A prospective study of young teenagers. British Medical Journal, 323, 480-484. 
Boyes, M. E., \& Cluver, L. (2013a). Performance of the Revised Children's Manifest Anxiety Scale in a sample of children and adolescents from poor urban communities in Cape Town. European Journal of Psycholgical Assessment, 29, 113-120.

Boyes, M. E., \& Cluver, L. (2013b). Relationships among HIV/AIDS-orphanhood, stigma, and symptoms of anxiety and depression in South African youth: A longitudinal investigation using a path analysis framework. Clinical Psychological Science, 1, 323-330.

Boyes, M. E., Cluver, L., \& Gardner, F. (2012). Psychometric properties of the Child PTSD Checklist in a community sample of South African children and adolescents. PLOS ONE, 7, e46905. DOI: 46910.41371/journal.pone.0046905.

Bronfrenbrenner, U. (1979). The ecology of human development: Experiments by nature and design. Cambridge, MA: Harvard University Press.

Brown, D., Riley, L., Butchart, A., \& Kann, L. (2008). Bullying among youth from eight African countries and associations with adverse health behaviours. Pediatric Health, 2, 289-299.

Brunstein Klomak, A., Marrocco, F., Kleinman, M., Schonfeld, I., \& Gould, M. (2007). Bullying, depression, and suicidality in adolescents. Journal of the American Academy of Child and Adolescent Psychiatry, 46, 40-49.

Burton, P. (2008). National primary school violence survey 2007. Cape Town: Centre for Justice and Crime Prevention.

Cluver, L., Bowes, L., \& Gardner, F. (2010). Risk and protective factors for bullying victimization among AIDS-affected and vulnerable children in South Africa Child Abuse and Neglect, 34, 793-803. 
Cluver, L., Gardner, F., \& Operario, D. (2007). Psychological distress amongst AIDSorphaned children in urban South Africa. Journal of Child Psychology and Psychiatry, 48, 755-763.

Cluver, L., Gardner, F., \& Operario, D. (2009). Poverty and psychological health among AIDS-orphaned children in Cape Town, South Africa. AIDS Care, 21, 732-741.

Cluver, L., Orkin, M., Boyes, M., Gardner, F., \& Nikelo, J. (2012). AIDS-orphanhood and cargiver AIDS-sickness status: Effects on psychological symptoms in South African youth. Journal of Pediatric Psychology, 37, 857-867.

Cluver, L., Orkin, M., Gardner, F., \& Boyes, M. E. (2012). Persisting mental health problems among AIDS-orphaned children in South Africa. Journal of Child Psychology and Psychiatry, 53, 363-370.

Coelho, R., Martins, A., \& Barros, H. (2002). Clinical profiles relating gender and depressive symptoms among adolescents ascertained by the Beck Depression Inventory II. European Psychiatry, 17, 222-226.

Cortina, M. A., Fazel, M., Hlungwani, T. M., Kahn, K., Tollman, S., Cortina-Borja, M., \& Stein, A. (2013). Childhood psychological problems in school settings in rural Southern Africa. PLOS ONE, 8, e65041, DOI: 65010.61371/journal.pone.0065041.

Eccles, J., Midgley, C., Wigfield, A., Buchannan, C., Reuman, D., Flanagan, C., \& Mac Iver, D. (1993). Development during adolescence: The impact of stage-environment fit on young adolescents' experiences in schools and in families. American Psychologist, 48, 90-101.

Fekkes, M., Pijpers, F., Fredriks, A., Vogels, T., \& Verloove-Vanhorick, S. (2006). Do bullied children get ill, or do ill children get bullied? A prospective cohort study on the relationship between bullying and health-related symptoms. Pediatrics, 117, 15681574. 
Field, A. (2005). Discovering statistics using SPSS (2nd ed.). London: Sage.

Flisher, A. J., Ward, C., Liang, H., Onya, H., Mlisa, N., Terblanche, S., . . Lombard, C. (2006). Injury-related behaviour among South African high-school students at six sites. South African Medical Journal, 96, 825-830.

Forero, R., McLellan, L., Rissel, C., \& Bauman, A. (1999). Bullying behaviour and associations with psychosocial health among school students in New South Wales, Australia: Cross-sectional survey. British Medical Journal, 319, 344-348.

Ghoul, A., Niwa, E., \& Boxer, P. (2013). The role of contingent self-worth in the relation between victimisation and internalising problems in adolescents. Journal of Adolescence, 36, 457-464.

Giaconia, R. M., Reinherz, H. Z., Silverman, A., Pakis, B., Frost, A., \& Cohen, E. (1993). Ages of onset of psychiatric disorders in a community population of older adolescents. Journal of the American Academy of Child and Adolescent Psychiatry, $33,707-716$.

Goodman, R. (1997). The Strengths and Difficulties Questionnaire: A research note. Journal of Child Psychology and Psychiatry, 38, 581-586.

Goodman, R., Meltzer, H., \& Bailey, V. (1998). The Strengths and Difficulties Questionnaire: A pilot study on the validity of the self-report version. European Child and Adolescent Psychiatry, 7, 125-130.

Hawker, D., \& Boulton, M. (2000). Twenty year's research on peer victimization and psychosocial maladjustment: A meta-analytic review of cross-sectional studies. Journal of Child Psychology and Psychiatry, 41, 441-455.

Kaltiala-Heino, R., Frojd, S., \& Marttunen, M. (2010). Involvement in bullying and depression in a 2-year follow-up in middle adolescence. European Child and Adolescent Psychiatry, 19, 45-55. 
Kaltiala-Heino, R., Rimpela, M., Rantanen, P., \& Rimpela, A. (2000). Bullying at school An indicator of adolescents at risk for mental disorders. Journal of Adolescence, 23, 661-674.

Kessler, R. C., Mcgonagle, K. A., Zhao, S., Nelson, C. B., Hughes, M., Eshleman, S., . . Kendler, K. S. (1994). Lifetime and 12-Month prevalence of DSM-III-R psychiatric disorders in the United States: Results from the national comorbidity survey. Archives of General Psychiatry, 51, 8-9.

Khatri, P., Kupersmidt, J. B., \& Patterson, C. (2000). Aggression and peer victimization as predictors of self-reported behavioral and emotional adjustment. Aggressive Behavior, $26,345-358$.

Kim, Y., Koh, Y., \& Leventhal, B. (2005). School bullying and suicidal risk in Korean middle school students. Pediatrics, 115, 357-363.

Kovacs, M. (1992). Children's Depression Inventory. Niagra Falls, NY: Multi-health Systems.

Larson, R., \& Richards, M. (1991). Daily companionship in late childhood and early adolescence: Changing developmental contexts. Child Development, 62, 284-300.

Lewinsohn, P. M., Gotlib, I. H., Lewinsohn, M., Seeley, J. R., \& Allen, N. B. (1998). Gender differences in anxiety disorders and anxiety symptoms in adolescents. Journal of Abnormal Psychology, 107, 109-117.

Liang, H., Flisher, A. J., \& Lombard, C. (2007). Bullying, violence, and risk behavior in South African school students. Child Abuse and Neglect, 31, 161-171.

McLean, C. P., \& Anderson, E. R. (2009). Brave men and timid women? A review of gender differences in fear and anxiety. Clinical Psychology Review, 29, 496-505. 
Michael, K. D., \& Merrell, K. W. (1998). Reliability of children's self-reported internalizing symptoms over short to medium length time intervals. Journal of the American Academy of Child and Adolescent Psychiatry, 37, 194-201.

Mulis, I. V. S., Martin, M. O., Kennedy, A. M., \& Foy, P. (2007). PIRLS 2006: IEAs progress in international reading literacy study in primary schools in 40 countries. Chestnut Hill, MA.

Mynard, H., \& Joseph, S. (2000). Development of the Multidimensional Peer Victimization Scale. Aggressive Behavior, 26, 169-178.

Nansel, T. R., Craig, W., Overpeck, M. O., Saluja, G., Ruan, W. J., \& Health Behavior in School-aged Children Analyses Working Group. (2004). Cross-national consistency in the relationship between bullying behaviors and psychosocial adjustment. Archives of Pediatric and Adolescent Medicine, 158, 730-736.

Nansel, T. R., Overpeck, M. O., Pilla, R. S., Ruan, W. J., Simons-Morton, B., \& Scheidt, P. (2001). Bullying behaviors among US youth: Prevalence and association with psychosocial adjustment. Journal of the American Medical Association, 16, 20942100.

Olweus, D. (1993). Bullying at school: What we know and what we can do. Oxford: Blackwell.

Pillay, U., Roberts, B., \& Rule, S. (2006). South African social attitudes: changing times, diverse voices. Cape Town: HSRC Press.

Reddy, S. P., Panday, S., Swart, D., Jinabhai, C. C., Amosun, S. L., James, S., . . Van den Borne, H. W. (2003). Umthenthe Uhlaba Usamila - The South African Youth Risk Behaviour Survey 2002. Cape Town: South African Medical Research Council. 
Reijntjes, A., Kamphuis, J., Prinzie, P., \& Telch, M. (2010). Peer victimization and internalizing problems in children: A meta-analysis of longitudinal studies. Child Abuse and Neglect, 34, 244-252.

Reynolds, C., \& Richmond, B. (1978). What I think and feel: A revised measure of children's anxiety. Journal of Abnormal Child Psychology, 6, 271-280.

Richter, L., \& Dawes, A. (2008). Child abuse in South Africa: Rights and wrongs. Child Abuse Review, 17, 79-93.

Rigby, K. (2002). New perspectives on bullying. London: Jessica Kingsley.

Rivers, I., \& Smith, P. K. (1994). Types of bullying behaviour and their correlates. Aggressive Behavior, 20, 359-368.

Rothon, C., Head, J., Klineberg, E., \& Stansfeld, S. (2011). Can social support protect bullied adolescents from adverse outcomes? A prospective study on the effects of bullying on the educational achievement and mental health of adolescents at secondary schools in East London. Journal of Adolescence, 34, 579-588.

Ruchkin, V., Schwab-Stone, M., \& Vermeiren, R. (2004). Social and Health Assessment (SAHA) psychometric development summary. New Haven: Yale University.

Salmivalli, C., \& Peets, K. (2009). Bullies, victims, and bully-victim relationships in middle childhood and early adolescence. In K. Rubin, M. Bukowski \& B. Laurens (Eds.), Handbook of peer interactions, relationships, and groups (pp. 322-340). New York: Guildford Press.

Schwartz, D., McFayden-Ketchum, S. A., Dodge, K. A., Pettit, G. S., \& Bates, J. E. (1998). Peer group victimization as a predictor of children's behavior problems at home and in school. Development and Psychopathology, 10, 87-99. 
Seedat, S., Nyamai, C., Njenja, F., Vythilingum, B., \& Stein, D. (2004). Trauma exposure and posttraumatic stress symptoms in urban African schools. British Journal of Psychiatry, 184, 169-175.

Shetgiri, R., Lin, H., \& Flores, G. (2012). Identifying children at risk for being bullies in the United States. Academic Pediatrics, 12, 509-522.

Shields, N., Nadasen, K., \& Pierce, L. (2009). A comparison of the effects of witnessing community violence and direct victimization among children in Cape Town, South Africa. Journal of Interpersonal Violence, 24, 1192-1208.

Siziya, S., Muula, A., \& Rudatsikira, E. (2007). Prevalence and correlates of truancy among adolescents from Swaziland: Findings from the Global School-Based Health Survey. Child and Adolescent Psychiatry and Mental Health, 1, 15.

Suliman, S., Mkabile, S. G., Fincham, D. S., Ahmed, R., Stein, D., \& Seedat, S. (2009). Cumulative effect of multiple trauma on symptoms of posttraumatic stress disorder, anxiety, and depression in adolescents. Comprehensive Psychiatry, 50, 121-127.

Tavakol, M., \& Dennick, R. (2011). Making sense of Cronbach's alpha. International Journal of Medical Education, 2, 53-55.

Townsend, L., Flisher, A. J., Chikobvu, P., Lombard, C., \& King, G. (2008). The relationship between bullying behaviours and high school dropout in Cape Town, South Africa. South African Journal of Psychology, 38, 21-32.

Ttofi, M. M., \& Farrington, D. P. (2011). Effectiveness of school-based programs to reduce bullying: a systematic and meta-analytic review. Journal of Experimental Criminology, 7, 27-56.

van der Wal, M., de Wit, C., \& Hirasing, R. (2003). Psychosocial health among young victims and offenders of direct and indirect bullying. Pediatrics, 111, 1312-1317. 
Visconti, K., \& Troop-Gordon, W. (2010). Prospective relations between children's responses to peer victimization and their socioemotional adjustment. Journal of Applied Developmental Psychology, 31, 261-272.

Vreeman, R. C., \& Carroll, A. E. (2007). A systematic review of school-based interventions to prevent bullying. Archives of Pediatric and Adolescent Medicine, 161, 78-88.

Williford, A., Boulton, A., Noland, B., Little, T. D., Karna, A., \& Salmivalli, C. (2012). Effects of the KiVa anti-bullying program on adolescent's depression, anxiety, and perception of peers. Journal of Abnormal Child Psychology, 40, 289-300.

Yen, C.-F., Huang, M.-F., Kim, Y., Wang, P.-W., Tang, T.-C., Yeh, Y.-C., . . Y Yang, P. (2013). Association between types of involvement in school bullying and different dimensions of anxiety symptoms and the moderating effects of age and gender in Taiwanese adolescents. Child Abuse and Neglect, 37, 263-272. 
Table 1. Sample characteristics disaggregated by gender

\begin{tabular}{|c|c|c|c|c|c|c|}
\hline & \multicolumn{3}{|c|}{ Baseline $(n=3515)$} & \multicolumn{3}{|c|}{ Follow-up $(n=3401)$} \\
\hline & Male & Female & $p$ & Male & Female & $p$ \\
\hline Live in urban area, $n(\%)$ & $789(52 \%)$ & $989(50 \%)$ & -- & $763(52 \%)$ & $957(50 \%)$ & -- \\
\hline Mpumlanga, $n(\%)$ & $751(49 \%)$ & $913(46 \%)$ & -- & $746(51 \%)$ & $902(47 \%)$ & -- \\
\hline Western Cape, $n(\%)$ & $772(51 \%)$ & $1079(54 \%)$ & .041 & $729(49 \%)$ & $1024(53 \%)$ & .030 \\
\hline Mean age $(S D)$ & $13.43(2.12)$ & $13.46(2.17)$ & .676 & $14.63(2.18)$ & $14.70(2.25)$ & .360 \\
\hline $\begin{array}{l}\text { Poverty - mean number of } \\
\text { necessities lacking }\end{array}$ & $2.66(2.31)$ & $2.76(2.33)$ & .187 & $2.61(2.33)$ & $2.87(2.36)$ & .002 \\
\hline
\end{tabular}

Note: Significant $p$ values are bolded. Significance levels are associated with $\chi^{2}$ from either a $2 \times 1$ contingency table (Gender) or a $2 \times 2$ contingency table, or one-way ANOVA (Age and Poverty). -- not applicable due to $2 \times 2$ contingency table (i.e. Gender $x$ Urban/Rural Location, Gender x Province). 
Table 2. Internalising and externalising symptoms at follow-up assessment disaggregated by bullying victimisation at baseline

\begin{tabular}{|c|c|c|c|c|c|c|}
\hline & $\begin{array}{l}\text { Any Bullying } \\
\text { Victimisation at } \\
\text { Baseline }\end{array}$ & $\begin{array}{l}\text { No Bullying } \\
\text { Victimisation at } \\
\text { Baseline }\end{array}$ & $p$ & $\begin{array}{l}\text { Four or More Types } \\
\text { of Bullying } \\
\text { Victimisation at } \\
\text { Baseline }\end{array}$ & $\begin{array}{l}\text { Less than Four Types } \\
\text { of Bullying } \\
\text { Victimisation at } \\
\text { Baseline }\end{array}$ & $p$ \\
\hline \multicolumn{7}{|l|}{ Internalising } \\
\hline $\begin{array}{l}\text { Follow-up anxiety, } M \\
\text { (SD) }\end{array}$ & $3.88(3.31)$ & $3.34(3.12)$ & $<.001$ & $6.19(3.78)$ & $3.49(3.12)$ & $<.001$ \\
\hline $\begin{array}{l}\text { Follow-up depression, } \\
M(\mathrm{SD})\end{array}$ & $1.23(2.04)$ & $1.54(2.33)$ & .441 & $2.35(3.05)$ & $1.31(2.10)$ & $<.001$ \\
\hline $\begin{array}{l}\text { Follow-up } \\
\text { posttraumatic stress, } M \\
\text { (SD) }\end{array}$ & $12.91(26.43)$ & $11.45(11.46)$ & .034 & $19.49(15.68)$ & $11.75(21.01)$ & $<.001$ \\
\hline \multicolumn{7}{|l|}{ Externalising } \\
\hline $\begin{array}{l}\text { Follow-up conduct } \\
\text { problems, } M(\mathrm{SD})\end{array}$ & $1.86(1.56)$ & $1.62(1.53)$ & $<.001$ & $2.67(1.86)$ & $1.69(1.51)$ & $<.001$ \\
\hline
\end{tabular}

Note: Significant $p$ values are bolded. Significance levels are associated with one-way ANCOVA (controlling for age, gender, poverty, urban versus rural location, and province. 
Table 3. Bullying victimisation, internalising symptoms, and externalising symptoms at baseline and follow-up assessments disaggregated by gender

\begin{tabular}{|c|c|c|c|c|c|c|}
\hline & \multicolumn{3}{|l|}{ Baseline $(n=3515)$} & \multicolumn{3}{|c|}{ Follow-up $(n=3401)$} \\
\hline & Male $(n=1523)$ & Female $(n=1992)$ & $p$ & Male $(n=1475)$ & Female $(n=1926)$ & $p$ \\
\hline Total Bullying Victimisation, $M(S D)$ & $13.75(4.95)$ & $13.63(4.88)$ & .534 & $12.84(4.01)$ & $12.61(3.87)$ & .109 \\
\hline $\begin{array}{l}\text { Verbal Bullying Victimisation, } M \\
(S D)\end{array}$ & $3.58(1.88)$ & $3.38(1.71)$ & .003 & $3.37(1.56)$ & $3.18(1.49)$ & .001 \\
\hline $\begin{array}{l}\text { Relational Bullying Victimisation, } M \\
(S D)\end{array}$ & $2.87(1.29)$ & $3.03(1.44)$ & .001 & $2.69(1.14)$ & $2.76(1.20)$ & .073 \\
\hline \multicolumn{6}{|l|}{ Victimisation, $M(S D)$} & .553 \\
\hline Physical proximity, $M(S D)$ & $1.27(.67)$ & $1.33(.73)$ & .042 & $1.20(.51)$ & $1.22(.54)$ & .377 \\
\hline Any Bullying Victimisation, $n(\%)$ & $53 \%$ & $52 \%$ & .407 & $46 \%$ & $46 \%$ & .722 \\
\hline $\begin{array}{l}\text { Experienced four or more types of } \\
\text { Bullying Victimisation, } n(\%)\end{array}$ & $13 \%$ & $13 \%$ & .960 & $6 \%$ & $6 \%$ & .845 \\
\hline \multicolumn{7}{|l|}{ Internalising Symptoms } \\
\hline Conduct Problems, $M(S D)$ & $1.84(1.79)$ & $1.64(1.62)$ & .001 & $1.88(1.61)$ & $1.65(1.50)$ & $<.001$ \\
\hline
\end{tabular}

Note: Significant $p$ values are bolded. Significance levels are associated with one-way ANCOVA (controlling for age, poverty, urban versus rural location, and province) or $\chi^{2}$. 


\section{$\underline{\text { Figure Caption }}$}

(Note - Figure 1 was constructed in Inkscape as a .png file. It was then converted to a TIFF file at 300 DPI). Figure 1 is also included as an additional file.

Figure 1 Cross-lagged models of relationships between multiple bullying victimisation and mental health.

Figure 1a Internalising symptoms (standardised coefficients and 95\% CIs are reported)

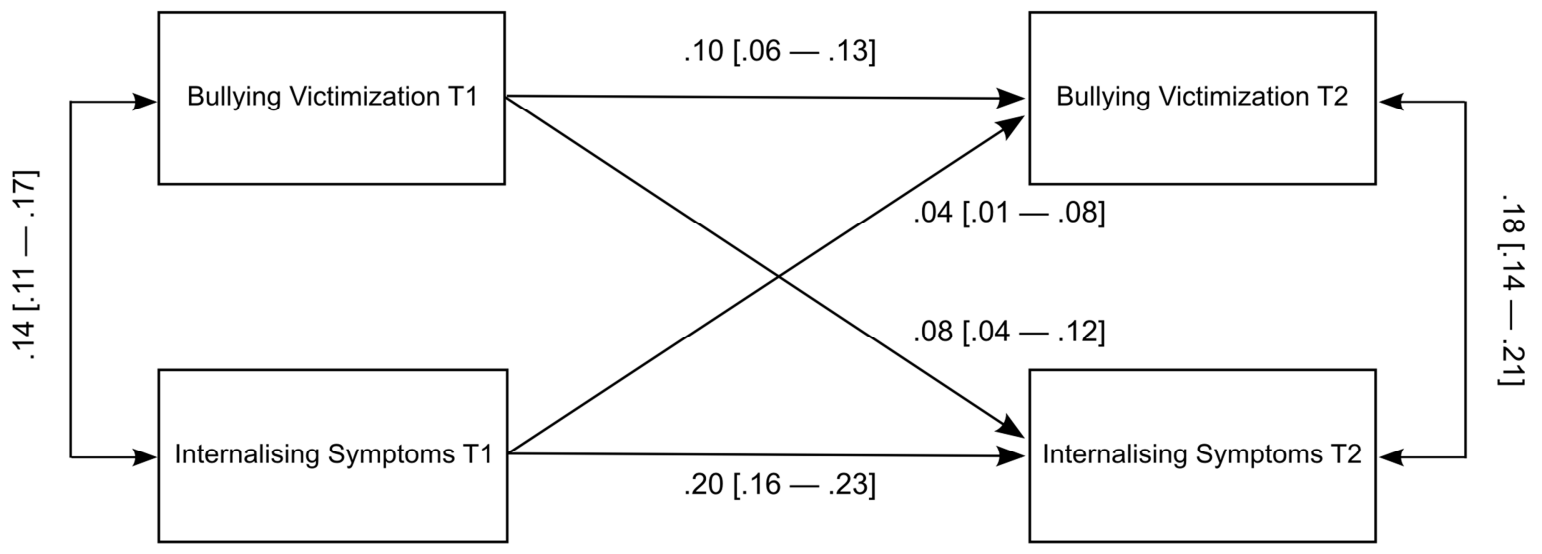

Figure 1b Conduct problems (standardised coefficients and 95\% CIs are reported)

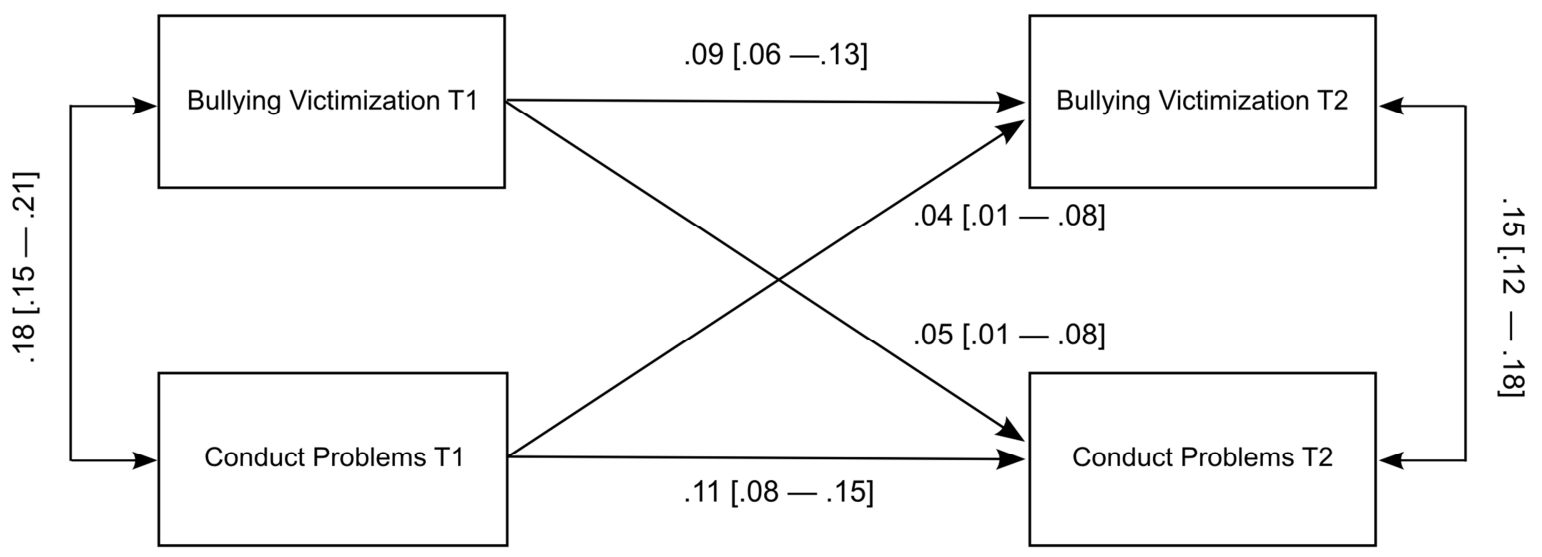

